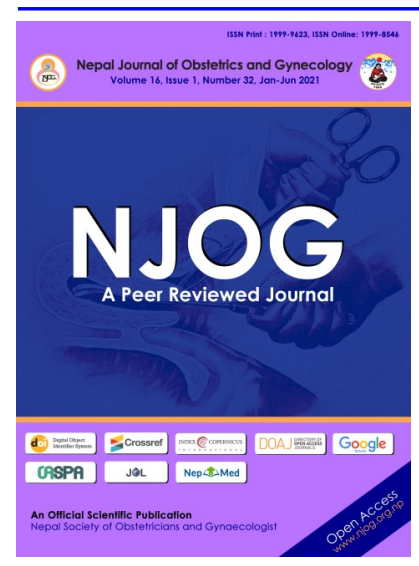

CORRESPONDENCE

Dr Oshan Shrestha

Department of Pathology, Nobel Medical College and Teaching Hospital, Biratnagar, Nepal

Email:

oshanpgi@gmail.com; Phone: +977-9841701161

Received: May1, 2021

Accepted: May20, 2021

\section{Citation:}

Shrestha O, Baral R, Shrestha S. Histomorphological Spectrum of Ovarian Masses in a Tertiary Centre of Eastern Nepal. Nep J Obstet Gynecol. 2021;16(32):103-107. DOI: https:// doi.org/10.3126/ njog.v16i1.37618

\title{
Histomorphological Spectrum of Ovarian Masses in a Tertiary Centre of Eastern Nepal
}

\author{
Oshan Shrestha, Reetu Baral, Shipra Shrestha \\ Department of Pathology, Nobel Medical College and Teaching Hospi- \\ tal, Biratnagar, Nepal
}

\section{ABSTRACT}

Aims: To analyze the trends of ovarian masses in a tertiary centre in eastern Nepal.

Methods: This was a retrospective cross sectional study conducted in Department of Pathology at Nobel Medical College and teaching hospital, Biratnagar, Nepal. Database of two years from April 2019 to April 2021 was searched. Gross and microscopic findings of cases including demographic details of patients with ovarian mass were analyzed and presented by descriptive parameters.

Results: Out of 127 cases of ovarian masses studied, 95 (74.8\%) were neoplastic. The common types were Germ cell tumors $(47 ; 37 \%)$, epithelial tumors $(43 ; 33.9 \%)$ and endometriotic cyst $(23 ; 18.1 \%)$. Mean age was 38.1 (range: 17-77) years in benign, $47.1(30-70)$ years in malignant and $36.9(21-53)$ years in non-neoplastic tumors; 11 cases were malignant and $63.6 \%$ were solid; and $23.8 \%$ of serous tumors were bilateral.

Conclusions: Benign neoplastic lesions were the most common lesions and presented earlier than borderline and malignant lesions. Endometriotic cysts comprised the most common non-neoplastic lesions. The non-neoplastic lesions were predominantly cystic and the malignant lesions were predominantly solid. Most of the benign lesions were solid-cystic. Most mucinous tumors and all the sex-cord stromal tumors were unilateral while the seromucinous tumor and a significant number of serous tumors were bilateral.

Keywords: histopathology, neoplastic, non-neoplastic, ovary

\section{INTRODUCTION}

Ovaries are a common site for both neoplastic and non-neoplastic lesions. They have extensive heterogeneity within and between histologic subtypes and the spectrum ranges from harmless simple cysts to aggressive malignant ones. ${ }^{1}$ Globally, ovaries are the third most common site of primary malignancy in female genital tract after cervix and endometrium. They are also the second most frequent cause of death from gynaecological cancers after cervical cancer. ${ }^{2}$ Ovarian tumors generally escape detection until they attain a large size. ${ }^{3}$

Even the physical examination, ultrasound and tumor markers aren't sufficient to differentiate neoplastic and non-neoplastic lesions. Grossly, most benign tumors of epithelial category are cystic, while the findings of necrosis, heterogeneous solid elements and papillary projections make malignancy more likely.

A thorough knowledge of the spectrum of ovarian disorders and its presentation is thus essential. The present study is undertaken to study the varying gross presentation, the histomorphological patterns and degree of differentiation for the specific diagnosis. This has tremendous significance to both pathologist and gynecologist for better understanding of the disease, its prognosis and planning proper patient management. ${ }^{8,9}$

\section{METHODS}

This is a retrospective cross sectional study performed in the Department of Pathology at Nobel Medical College, Biratnagar, Nepal. It was conducted over a period of 2 years from April 2019 to April 2021. Surgically managed cases with ovarian masses su- 
bmitted to the Pathology lab were included in the study irrespective of the surgical modality. Thus, cystectomy, oophorectomy, salpingo-oophorectomy and total abdominal hysterectomy with unilateral or bilateral salpingo-oophorectomy were included in the study.

The specimens were fixed in $10 \%$ neutral buffered formalin. Gross appearance, laterality and size were noted and representative sections taken. The tissues were processed and stained with Hematoxylin and Eosin stain as per standard protocol. The slides were then examined microscopically by Pathologists. Histologic categorisation was done according to World Health Organization (WHO $5^{\text {th }}$ edition) guidelines. The variables were entered in a database and data were analysed in SPSS version 20.0

\section{RESULTS}

Out of 127 specimens with ovarian mass received in the Pathology Department, 95 (74.8\%) were neoplastic with $83(87.4 \%)$ benign, $11(11.5 \%)$ malignant and $1(1.1 \%)$ borderline tumors respectively. [Figure-1]

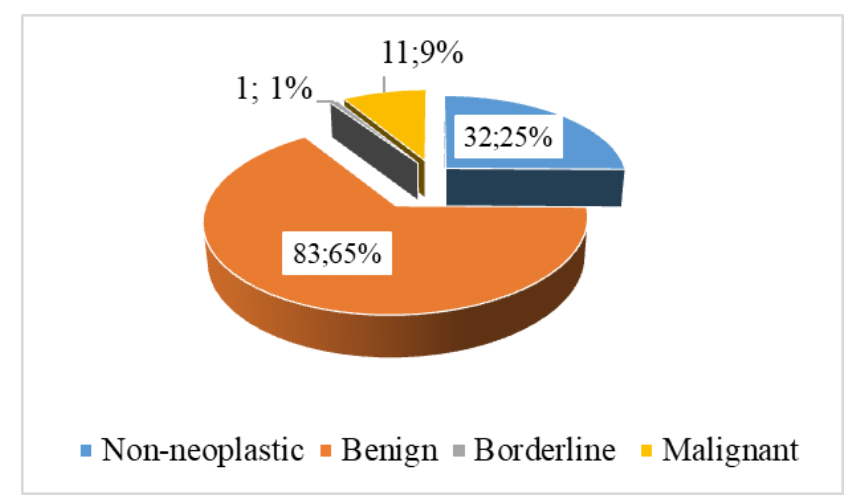

Figure-1: Distribution of ovarian masses

The mean age of patients was 38.1 (range: 17-77) years in benign, $47.1(30-70)$ years in malignant, 47 years in borderline (single case) and 36.9 (21-53) years in non-neoplastic tumors. [Figure-2]

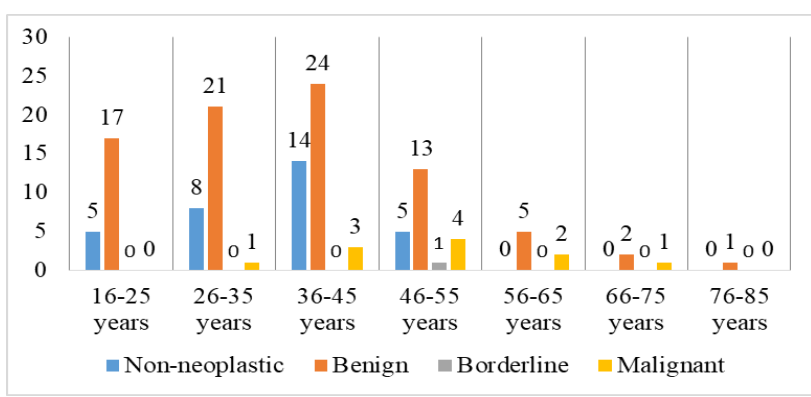

Figure-2: Age wise frequency distribution of ovarian masses
Germ cell tumors were the most common neoplasms were Germ cell tumor (49.5\%) followed by epithelial (45.2\%) and sex-cord stromal tumor $(5.3 \%)$. Only two of the $47(4.3 \%)$ germ cell tumors were malignant. Serous cystadenoma was the most common surface epithelial tumor followed by mucinous cystadenoma. There were 11 malignant tumors with high grade serous carcinoma being the commonest malignancy followed by mucinous carcinoma. In the non-neoplastic category, endometriotic cyst was the most common $(23 ; 71.9 \%)$ followed by corpus luteal cyst. [Table-1]

Table-1: Histopathological category of ovarian mass $(\mathrm{N}=127)$

\begin{tabular}{|c|c|c|}
\hline Category & Morphological diagnosis & $\sum$ \\
\hline \multirow{3}{*}{ 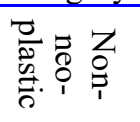 } & Endometriotic cyst & 23 \\
\hline & Corpus luteal cyst & 8 \\
\hline & Pelvic inflammatory disease & 1 \\
\hline \multirow{4}{*}{ 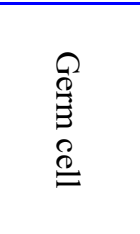 } & Mature cystic teratoma & 44 \\
\hline & Struma ovarii, NOS & 1 \\
\hline & $\begin{array}{l}\text { Germ cell + yolk sac component } \\
\text { (Malignant) }\end{array}$ & 1 \\
\hline & $\begin{array}{l}\text { SCC in mature cystic teratoma } \\
\text { (Malignant) }\end{array}$ & 1 \\
\hline \multirow{9}{*}{ 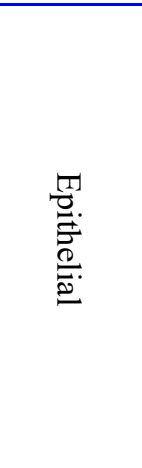 } & Serous cystadenoma & 21 \\
\hline & Mucinous cystadenoma & 11 \\
\hline & $\begin{array}{l}\text { High grade serous carcinoma } \\
\text { (Malignant) }\end{array}$ & 4 \\
\hline & Mucinous carcinoma (Malignant) & 2 \\
\hline & Seromucinous cystadenoma & 1 \\
\hline & Seromucinous borderline tumor & 1 \\
\hline & Brenner tumor & 1 \\
\hline & $\begin{array}{l}\text { Endometrioid carcinoma } \\
\text { (Malignant) }\end{array}$ & 1 \\
\hline & $\begin{array}{l}\text { Ovarian mesonephric like adeno- } \\
\text { carcinoma (Malignant) }\end{array}$ & 1 \\
\hline \multirow{3}{*}{ 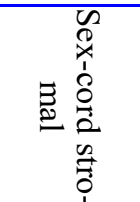 } & $\begin{array}{l}\text { Adult granulosa cell tumor } \\
\text { (Benign) }\end{array}$ & 3 \\
\hline & $\begin{array}{l}\text { Adult granulosa cell tumor } \\
\text { (Malignant) }\end{array}$ & 1 \\
\hline & Ovarian fibroma & 1 \\
\hline
\end{tabular}

The non-neoplastic masses were predominantly cystic (93.8\%) while only 2 cases out of 32 were solid-cystic. In the benign category, $60.2 \%$ of cases were solid-cystic, while $35 \%$ were cystic. Solid masses comprised only $4.8 \%$ of the benign tumors. The malignant tumors were however predominantly solid $(63.6 \%)$. One case in the malignant category was cystic and 3 were solid-cystic in nature. [Figure-3]

Taking into account the largest dimension, mean diameter of non-neoplastic, benign and malignant masses were $5.4 \mathrm{~cm}, 8.6 \mathrm{~cm}$ and $12.4 \mathrm{~cm}$ respectively. The single borderline tumor measured $12 \mathrm{~cm}$ 
in largest dimension. Only one of the 13 mucinous neoplasms were bilateral while the rest $(92.3 \%)$ were unilateral. Serous tumors were however bilateral in $23.8 \%$ of cases. All the sex-cord stromal tumors were unilateral and all the seromucinous tumors were bilateral. [Figure-4]

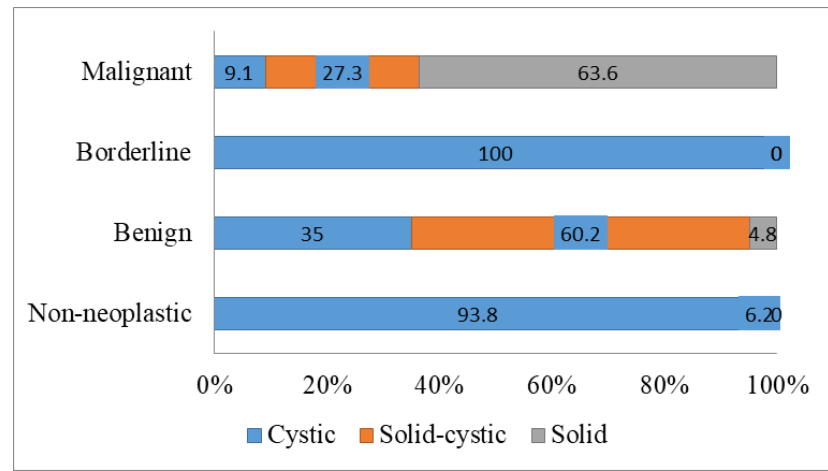

Figure-3: Distribution of ovarian lesions according to gross presentations

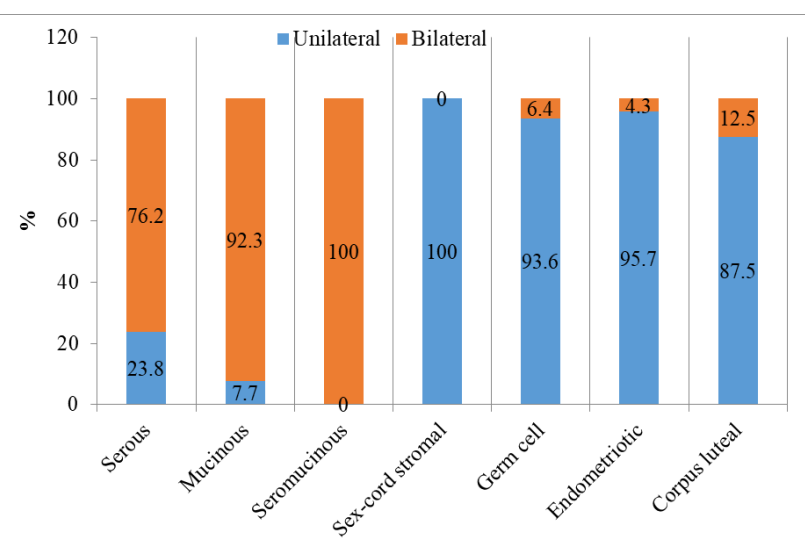

Figure-4: Distribution of ovarian masses by laterality

\section{DISCUSSION}

Among the 127 cases studied, 95 (74.8\%) were neoplastic and $32(25.2 \%)$ were non-neoplastic. The incidences of non-neoplastic lesions were higher in Indian studies i.e. $51.7 \%$ and $87.3 \%$ in studies conducted by Kanthikar et $\mathrm{al}^{10}$ and Pudasaini et $\mathrm{al}^{11}$ respectively. Our finding is however consistent with the observation in a similar study in central Nepal ${ }^{12}$ with $24 \%$ non-neoplastic cases. Vast majority of the ovarian tumors in our study belonged to benign category with mature cystic teratoma being the predominant one. This finding is also in corroboration with other studies. ${ }^{13-15}$

Benign tumors were also common in younger age group with the mean age being 37.5 years as opposed to the aggressive tumors which were more common in older age group. This finding is also consistent with that of other studies that showed malignant ovarian tumors more frequent in older females. ${ }^{16-18}$ Only one case of surface epithelial tumor and both the cases of malignant germ cell tumor were below 40 years of age. All the other malignant ovarian tumors comprised patients more than 40 years. Thus, our study agrees with other studies that malignant germ cell tumors frequently present in a younger population. ${ }^{19,20}$

High grade serous carcinomas was the most common malignancy in our study that is in accordance with the results obtained by other studies. ${ }^{15,21}$ Likewise, endometriotic cyst was the most common non-neoplastic mass $(71.9 \%)$ followed by corpus luteal cyst $(25 \%)$. This finding also matches with that of other literatures. ${ }^{12,14}$

The predominantly cystic lesions were nonneoplastic and the solid-cystic lesions were mostly benign germ cell tumors. Most of the predominantly solid lesions were malignant and only 2 cases in the malignant category were cystic. This is also in agreement with other studies on ovarian tumors. ${ }^{10,22-24}$

As seen in the study by Kaur et $\mathrm{al}^{25}$, malignant lesions had a larger mean dimension than benign and non-neoplastic lesions. However, size of the only benign seromucinous tumor and some benign mucinous tumors in our study exceeded that of malignant tumors. Similar finding of larger mucinous cystadenomas were noted by Zaman et al. ${ }^{26}$ Hence tumor dimension alone may not be of much help to distinguish benign and malignant lesions.

All the seromucinous tumors and most of the mucinous epithelial tumors, regardless of their nature were bilateral. One of the limitations is that our study had only 2 cases with seromucinous phenotype. Moreover, our study showed a significant number of serous neoplasms and all the sex-cord stromal tumors to be unilateral. Similar observations had been made before in clinical series. ${ }^{4,5,27,28}$

\section{CONCLUSIONS}

Benign neoplastic lesions were the most common lesions and presented earlier than borderline and malignant lesions. Endometriotic cysts comprised the most common non-neoplastic lesions. The nonneoplastic lesions were predominantly cystic and the malignant lesions were predominantly solid. 
Most of the benign lesions were solid-cystic. Most mucinous tumors and all the sex-cord stromal tumors were unilateral while the seromucinous tumor and a significant number of serous tumors were bilateral.

\section{REFERENCES}

1. Vaughan S, Coward JI, Bast RC, Berchuck A, Berek JS, Brenton JD, et al. Rethinking ovarian cancer: recommendations for improving outcomes. Nat Rev Cancer. 2011;11(10):719-25.

2. Bray F, Ferlay J, Soerjomataram I, Siegel RL, Torre LA, Jemal A. Global cancer statistics 2018: GLOBOCAN estimates of incidence and mortality worldwide for 36 cancers in 185 countries. CA Cancer J Clin. 2018;68(6):394-424.

3. Doubeni CA, Doubeni AR, Myers AE. Diagnosis and Management of Ovarian Cancer. Am Fam Physician. 2016;93(11):937-44.

4. Hart WR. Mucinous tumors of the ovary: a review. Int J Gynecol Pathol Off J Int Soc Gynecol Pathol. 2005;24(1):4-25.

5. Mills AM, Shanes ED. Mucinous Ovarian Tumors. Surg Pathol Clin. 2019;12(2):565-85.

6. Nakashima N, Young RH, Scully RE. Androgenic granulosa cell tumors of the ovary. A clinicopathologic analysis of 17 cases and review of the literature. Arch Pathol Lab Med. 1984;108 (10):786-91.

7. Morency E, Leitao MM, Soslow RA. Low-stage high-grade serous ovarian carcinomas: support for an extra-ovarian origin. Int J Gynecol Pathol Off J Int Soc Gynecol Pathol. 2016;35(3):222-9.

8. Vergote I, De Brabanter J, Fyles A, Bertelsen K, Einhorn N, Sevelda P, et al. Prognostic importance of degree of differentiation and cyst rupture in stage I invasive epithelial ovarian carcinoma. The Lancet. 2001;357(9251):176-82.

9. Ezzati M, Abdullah A, Shariftabrizi A, Hou J, Kopf M, Stedman JK, et al. Recent Advancements in Prognostic Factors of Epithelial Ovarian Carcinoma. Int Sch Res Not. 2014;2014:e953509.

10.Kanthikar SN, Dravid NV, Deore PN, Nikumbh DB, Suryawanshi KH. Clinico-Histopathological Analysis of Neoplastic and Non-Neoplastic Lesions of the Ovary: A 3-Year Prospective Study in Dhule, North Maharashtra, India. J Clin Diagn Res JCDR. 2014;8(8):FC04-7.

11.Pudasaini S, Lakhey M, Hirachand S, Akhter J, Thapa B. A study of ovarian cyst in a tertiary hospital of Kathmandu valley. Nepal Med Coll. 2011;13(1):39-41.
12. Sherpa P, Baral R. Histopathological Profile of Ovarian Masses. Nepal J Obstet Gynaecol. 2017;12(2):36-9.

13. Kayastha S. Study of ovarian tumours in Nepal Medical College Teaching Hospital. Nepal Med Coll. 2009;11(3):200-2.

14. Sharadha S, Sridevi TA, Renukadevi TK, Gowri R, Binayak D, Indra V. Ovarian masses: changing clinico histopathological trends. J Obstet Gynaecol India. 2015;65(1):34-8.

15.Mansoor NA, Jezan HS. Spectrum of ovarian tumors: Histopathological study of 218 cases. Gulf J Oncolog. 2015;1(18):64-70.

16. Quirk JT, Natarajan N. Ovarian cancer incidence in the United States, 1992-1999. Gynecol Oncol. 2005;97(2):519-23.

17.Saeed M, Khawaja K, Rizwana I, Malik I, Rizvi J, Khan A. A clinicopathological analysis of ovarian tumours. J Pak Med Assoc. 1991;41 (7):161-4.

18. Yancik R. Ovarian cancer: Age contrasts in incidence, histology, disease stage at diagnosis, and mortality. Cancer. 1993;71(S2):517-23.

19. Shaaban AM, Rezvani M, Elsayes KM, Baskin H, Mourad A, Foster BR, et al. Ovarian Malignant Germ Cell Tumors: Cellular Classification and Clinical and Imaging Features. Radio Graphics. 2014;34(3):777-801.

20.Tewari K, Cappuccini F, Disaia PJ, Berman ML, Manetta A, Kohler MF. Malignant germ cell tumors of the ovary. Obstet Gynecol. 2000;95(1):128-33.

21.Mondal SK, Banyopadhyay R, Nag DR, Roychowdhury S, Mondal PK, Sinha SK. Histologic pattern, bilaterality and clinical evaluation of 957 ovarian neoplasms: a 10-year study in a tertiary hospital of eastern India. J Cancer Res Ther. 2011;7(4):433-7.

22.Agrawal P, Kulkarni D, Chakrabarti P, Chourasia S, Dixit M, Gupta K. Clinicopathological spectrum of ovarian tumors: A 5-year experience in a tertiary health care center. J Basic Clin Reprod Sci. 2015;4:90.

23.Pilli GS, Suneeta KP, Dhaded AV, Yenni VV. Ovarian tumours: a study of 282 cases. J Indian Med Assoc. 2002;100(7):420, 423-4, 447. 
25.Kaur A, Faujdar M, Kariya T, Gupta S. Histomorphological spectrum of Ovarian tumors in a tertiary care hospital. Ann Woman Child Health. 2017;3:A52-61.

26.Zaman S, Majid S, Hussain M, Chughtai O, Mahboob J, Chughtai S. A retrospective study of ovarian tumours and tumour-like lesions. J Ayub Med Coll Abbottabad . 2010;22(1):104-8.
27. Leake JF, Currie JL, Rosenshein NB, Woodruff JD. Long-term follow-up of serous ovarian tumors of low malignant potential. Gynecol Oncol. 1992;47(2):150-8.

28. Boger-Megiddo I, Weiss NS. Histologic subtypes and laterality of primary epithelial ovarian tumors. Gynecol Oncol. 2005;97(1):80-3. 